\title{
Chávez e Petróleo: Uma Análise da Nova Política Econômica Venezuelana
}

\author{
Pedro Silva Barros*
}

Resumo: A partir da concepção de que o governo Hugo Chávez tem uma política econômica em processo e a economia venezuelana é marcadamente rentista, o artigo discutirá os determinantes da dinâmica econômica e política venezuelana a partir de 1999. Para tal, dividimos o texto em duas partes. Na primeira discutiremos a importância do petróleo para a economia venezuelana e sua influência na vida política do país, principalmente após a criação da companhia estatal de petróleo. Na segunda parte buscaremos entender a política econômica chavista a partir da apresentação e discussão de seu projeto político-econômico em quatro momentos distintos.

Palavras-chave: Venezuela, Hugo Chávez, Política Econômica, Petróleo.

Abstract: Under the perspective that Hugo Chávez `economics policy are a continuous process and that Venezuela economics is based on the gas and oil exploration, the article discuss the most important aspects to determinate the economic dynamism and the State politics since 1999. For that reason, the text is built in two parts. In the first part we argue about the gas and oil importance to the Venezuela economics and the way it interferes in the State politics. In the second part we try to understand Chávez ' economic policy based on his economical and political project during four different moments.

Keywords: Venezuela, Hugo Chávez, Economics Policy, Oil.

\footnotetext{
* Professor do Depto. de Economia da Pontifícia Universidade Católica de São Paulo (PUC-SP). E-mail: psbarros@pucsp. br. Recebido em 12/11/06 e aceito em 12/12/06.
} 


\section{Introdução}

A partir da concepção de que o governo Hugo Chávez tem uma política econômica em processo o artigo discutirá os determinantes da dinâmica econômica e política venezuelana a partir de 1999. O texto parte da análise que a economia venezuelana é rentista ${ }^{1}$, desde a descoberta do petróleo em 1928, e sua relação com o Estado viveu dois períodos bastante distintos nos anos 1960-1970 e 1980-1990. No primeiro período os preços internacionais do petróleo subiram de maneira bastante significativa e as benesses das exportaçóes do produto chegavam a diversos setores sociais; no período seguinte ocorreu o inverso, a queda das receitas petroleiras fez com que somente os grupos sociais mais próximos à PDVSA (companhia estatal de petróleo criada em 1976) e ao Estado se beneficiassem da renda petroleira.

A exclusão de amplos setores sociais repercutiu eleitoralmente; a oposição venceu as eleições de 1989 e 1994 com discursos de retorno aos tempos áureos. Mas as promessas eleitorais não se concretizaram; ao primeiro sinal de crise, ambos os governos aderiram às reformas de cunho neoliberal. As mudanças promovidas pelos governos venezuelanos na década de noventa foram bastante silenciosas se comparada a outros países sul-americanos, notadamente Argentina e Chile, embora também estivesse associada às idéias do Consenso de Washington ${ }^{2}$. O mais importante ponto da agenda neoliberal venezuelana era a abertura petroleira. Essa ruptura peculiar não passava pelo alarde que seria a venda da PDVSA para uma transnacional petroleira, mas pelo retorno de investimentos privados à atividade petroleira e pela desregulamentação do setor, que acarretava inclusive na diminuição dos tributos e royalties repassados ao governo.

$\mathrm{Na}$ eleição de 1998, ano em que os preços internacionais do petróleo

\footnotetext{
${ }^{1}$ Nas palavras de Jorge Giordani, professor da Universidad Central de Venezuela e ministro do planejamento desde dezembro de 1998, "a Venezuela continua vivendo da dita renda petroleira, que não se produz, mas sim se capta" (GIORDANI, 2005). O documento "Hacia Una Venezuela Productiva" do Ministério do Desenvolvimento e Planejamento da Venezuela, de setembro de 2004, inicia-se com a seguinte afirmação: "a Venezuela continua sendo um país rentista, cuja riqueza majoritariamente vem captada do exterior mediante a apropriação de um excedente que permitiu, com a exportação petroleira, manter um saldo comercial e de serviços positivos para o páís” (MPD, 2004).

${ }^{2}$ Denominação para as conclusões de reunião ocorrida na capital americana que participaram funcionários do governo daquele país, do FMI, do BIRD, do BID e economistas latino-americanos. Nelas, se destacam, entre outras: abertura econômica com redução das barreiras protecionistas, privatização de empresas estatais e flexibilização das relações de trabalho e desregulamentação e fim das restrições para o movimento de capital (BATISTA, 1994).
} 
atingiram seu mais baixo patamar desde o choque de 1979, a alternância de poder entre os partidos do pacto de Punto Fijo ${ }^{3}$ ruiu. O militar e exgolpista Hugo Chávez assumiu o poder, naquela que é considerada por muitos a primeira alternativa latino-americana de saída do neoliberalismo e, consequentemente, de ruptura com o Consenso de Washington.

O texto será dividido em duas partes. A primeira discutirá os determinantes que levaram à ascensão de Hugo Chávez à presidência da Venezuela, destacando a influência do petróleo na vida política e econômica do país, principalmente após a criação da PDVSA. A segunda parte busca entender a política econômica chavista a partir de 1998. Para tal apresentaremos e discutiremos seu projeto político-econômico em quatro momentos. O primeiro trata do período anterior à chegada ao poder; resgataremos o programa de governo do Movimento V República, partido que chegou ao poder nas eleições de 1998. O segundo trata do início do governo Chávez, nele ressaltamos a importância do ortodoxo "Programa Econômico de Transição 1999-2000" para a garantia da estabilidade necessária para a elaboração e aprovação da Constituição Bolivariana de 1999, alicerce do projeto político chavista. O terceiro trata da inflexão política e econômica provocada pelas Leis Habilitantes de novembro de 2001 e da resposta conservadora explicitada na tentativa de golpe de Estado em abril de 2002 e na greve patronal-petroleira de dezembro de 2002 a fevereiro de 2003. Por fim, no quarto momento, trataremos do Estado controlado e da nova política econômica venezuelana; analisaremos se o vigoroso crescimento econômico do país nos anos de 2004 e 2005 é mero reflexo das quedas no PIB nos anos de 2002 e 2003 e da alta dos preços do petróleo ou se nele já repercute os efeito das propaladas missóes sociais econômicas e as políticas de desenvolvimento endógeno.

\section{História e petróleo: os determinantes da ascensão de Hugo Chávez}

A Venezuela é um país petroleiro desde a década de 1920, quando o petróleo superou o café como principal produto de exportação.

\footnotetext{
${ }^{3}$ Período de alternância de poder instituído após a ditadura de Pérez Jiménez (1950-58) entre os partidos COPEI e a AD que vigorou por quarenta anos, até a eleição de Hugo Chávez em 1998 (GONZÁLEZ, 2001). O período também é conhecido na bibliografia venezuelana como "democracia representativa", "democracia formal" (MALAVÉ MATA, 1987) e "IV República", para os chavistas.
} 
Tabela 1 - Composição das exportaçóes, 1920 - 1935 (milhóes em bolívares)

\begin{tabular}{|c|c|c|c|c|c|c|c|}
\hline Anos & Totais & Petrolíferas & $\mathbf{\%}$ & $\begin{array}{c}\text { Café e } \\
\text { cacau }\end{array}$ & \% & Outras & \% \\
\hline 1920 & 173,3 & 3,1 & 1,7 & 100,7 & 58,1 & 69,5 & 40,2 \\
\hline 1925 & 373,1 & 173,9 & 46,6 & 155,2 & 41,6 & 44 & 11,8 \\
\hline 1935 & 528,9 & 455,3 & 86,1 & 37,7 & 7,1 & 35,9 & 6,8 \\
\hline
\end{tabular}

FONTE: Baptista, 1991, p. 66

Como a maioria dos países latino-americanos, a Venezuela vivia da monocultura agrícola para exportação (principalmente café e cacau) e da agricultura de subsistência. Ao submeter seu projeto de desenvolvimento ao objetivo de ser um grande exportador de petróleo, a Venezuela passa a ser, paradoxalmente, um país isolado dos vizinhos. Exporta petróleo, importa o resto; principalmente dos Estados Unidos ${ }^{4}$. Desde a década de 1970 o petróleo responde por mais de $75 \%$ das exportaçóes, $50 \%$ da arrecadação do Estado e entre $25 \%$ e $30 \%$ do produto venezuelano.

Em 1976 a Venezuela, como muitos outros paises, nacionalizou a indústria petroleira. Acreditava-se que a estatal PDVSA seria a casa matriz de um conjunto de empresas que até a noite anterior eram transnacionais, mas o que se viu nos anos seguintes foi o descolamento da administração da empresa para longe dos interesses da sociedade venezuelana. A excessiva autonomia da PDVSA resultou na política de apertura petrolera iniciada no governo Carlos Andrés Pérez (LANDER, 2002).

Durante 40 anos (1958-1998) prevaleceu na Venezuela o pacto de Punto Fijo, que garantiu a ordem institucional e uma democracia formal na qual $\mathrm{AD}$ e COPEI mantiveram políticas similares em quase todos os aspectos. Entretanto, com o passar dos anos, a prática política dos dois partidos levou a uma abstenção e a uma apatia política cada vez maiores. Além disso, ela garantiu a perpetuação de uma estrutura social muito desigual já que o petróleo estava nas mãos de um grupo oligárquico.

O sistema funcionou bem durante toda a década de 1970, devido, sobretudo, aos altos preços do petróleo ${ }^{5}$. Entretanto, na década de 1980 a

\footnotetext{
${ }^{4}$ Desde a década de 1950 os Estados Unidos da América são responsáveis por mais da metade, nos dois lados da balança, do comércio exterior da Venezuela.

${ }^{5} \mathrm{O}$ preço do barril do petróleo chegou aos US\$ 40,00 em 1979, no começo daquela década estava abaixo dos US\$ 4,00 (valores não corrigidos).
} 
fartura chegou ao fim: os preços do petróleo desabaram e a Venezuela não ficou imune à crise da dívida que atropelou qualquer tentativa de desenvolvimento de quase todos os países da América Latina.

O longo período que Venezuela tentou superar a crise econômica, social e política dentro dos marcos de Punto Fijo pode ser dividido em duas etapas de formulação e execução de políticas de modernização (GONZÁLEZ, 2001, p. 56). A primeira etapa começa com o entendimento das elites políticas de que tanto o modelo de desenvolvimento como o modelo político vigentes estavam em crise, o que ficou claro na campanha presidencial vitoriosa de Jaime Lusinchi (1984-1989) que, no final de 1983, propôs a elaboração de um "pacto social" para re-fundar Punto Fijo. Embora tenha apresentado algumas mudanças importantes como a eleição direta para governadores, a principal contribuição histórica desta etapa foi colocar a pauta da reforma do Estado na ordem do dia da sociedade venezuelana.

A segunda etapa, sob forte influência do Consenso de Washington, é caracterizada pela agenda de abertura e liberalização da economia. Carlos Andrés Pérez (1989-1993) foi eleito, para seu segundo governo, com um discurso de retorno aos áureos tempos da bonança petroleira amparado pelo programa "El Gran Viraje”, mas se viu a beira da insolvência e optou por " $E l$ Paquete”, como ficaram popularmente conhecidas as reformas que o governo procurou

realizar, a un ritmo que podríamos catalogar de imprudentemente acelerado, un conjunto de reformas destinadas a desmontar al Estado Populista y a lograr un nuevo modelo de desarrollo baseado en la apertura hacia los mercados esternos y la promoción de las exportaciones no tradicionales (GONZÁLEZ, 2001, p. 56).

O programa de Carlos Andrés Pérez incluía o fim de vários subsídios, aumento dos tributos e das tarifas públicas, liberalização das taxas de juros, flexibilização do câmbio, abertura comercial e privatizaçóes. A execução do programa não foi tão tranqüila como nos áureos tempos de Punto Fijo. Amplos setores sociais que haviam perdido participaçáo nas benesses do Estado petroleiro não se sentiam mais representados no pacto social vigente. 
$\mathrm{Na}$ Venezuela a essência do neoliberalismo dos anos noventa foi a desvinculação entre PDVSA e Estado. Em 1981, por exemplo, os ingressos brutos gerados pelas exportaçóes de petróleo somaram US\$19,1 bilhóes dos quais o Estado venezuelano arrecadou US\$ 13,9 bilhóes em impostos; em 2000 os ingressos brutos pela exportação de petróleo totalizou US\$ 27,3 bilhôes, mas a arrecadação ficou apenas em US\$ 11,3 bilhões (BOUÉ, 2002). A PDVSA, por sua vez, na segunda metade da década de noventa, transferiu uma média anual de US\$ 500 milhōes a suas filiais no exterior (BOUÉ, 2002), no início dos anos oitenta estas transferências eram insignificantes.

Uma das primeiras medidas dos segundo governo de Carlos Andrés Pérez foi, ainda em fevereiro de 1989, aumentar os preços dos combustíveis na bomba. A conseqüência desta atitude, até certo ponto inesperada, foi uma revolta popular até hoje pouco compreendida. Para Richard GOTT, jornalista britânico do The Guardian e correspondente do jornal na Venezuela e em outros países da América Latina por vários anos, o Caracazo de 1989, como ficou conhecida a revolta popular, era "anárquico, caótico e não tinha liderança” (GOTT, 2004, p. 73). O episódio foi tão inesperado que o Estado não estava preparado para reprimi-lo e os grupos políticos críticos ao sistema também não estavam preparados para apropriá-lo. O autor recorda que Carlos Andrés Pérez, logo após ter sido eleito, viajou para a Arábia Saudita, Kuait e Argélia levando os analistas a preverem que o seu governo tentaria rearticular a Opep e teria uma política internacional e econômica parecida com a que seu primeiro governo tivera. Mas

quando chegou em Caracas já tinha tudo organizado. Para surpresa de todos, decidira aderir à política da revolução neoliberal em voga, que naquele momento ainda náo se transformara na nova ortodoxia dos anos 1990. Pérez provavelmente não via outro caminho a seguir (GOTT, 2004, p. 84).

As reformas neoliberais de Carlos Andrés Pérez seguiam e, em fevereiro de 1992, após aprovar a Lei de Privatizaçóes, um grupo de militares de baixa patente liderados pelo tenente-coronel Hugo Chávez fracassou na tentativa de derrubar o governo através de um golpe militar. Os participantes do movimento armado foram presos; mas em novembro do mesmo ano 
ocorreu nova tentativa de golpe, agora muito mais violenta, liderada pelo vice-almirante Hernán Grüber. Ambas tentativas não tiveram imediato apoio popular, porém Hugo Chávez, mesmo preso, se converteu na principal referência de oposição ao bipartidarismo venezuelano.

Um impeachment por corrupção marcou o fim do governo Carlos Andrés Pérez. O processo eleitoral de 1993 explicitou a decadência de Punto Fijo ao repercutir a crise econômica, o Caracazo e as duas tentativas de golpe. A taxa de abstenção do eleitorado aumentou de $25 \%$, no pleito de 1988, para $40 \%$ e a $\mathrm{AD}$ e o COPEI, que desde a eleição de 1973 tinham (somados) mais de $83 \%$ dos votos, tiveram juntos apenas 46\%. Rafael Caldera, embora fosse historicamente ligado ao COPEI (foi o representante do partido nas negociaçóes de Punto Fijo, nos anos cinqüenta, e eleito presidente, em 1968), só chegou ao poder porque saiu do partido, se aliou ao MAS (Movimento ao Socialismo; partido de esquerda dissidente do PCV que reunia intelectuais e ex-guerrilheiros dos anos sessenta, notadamente Teodoro Petkoff) e, em discurso no Congresso em 1992, deu legitimidade à tentativa de golpe de Hugo Chávez. Uma das primeiras atitudes do segundo governo de Rafael Caldera (1994-1998) foi indultar Hugo Chávez e os participantes dos dois golpes de 1992 .

Eleito com apenas 30\% dos votos, o governo de Rafael Caldera teve grande dificuldade para executar seu programa de governo, que incluía reverter algumas privatizaçóes do governo anterior. Sem conseguir angariar muitos apoios e constrangido pela instabilidade econômica, Caldera repactua com a AD e retoma, com o nome de "Agenda Venezuela", o programa de reformas de Carlos Andrés Pérez.

A questáo petroleira explicita a dinâmica dos dois governos do fim de Punto Fijo. Carlos Andrés Pérez tentou no início de seu governo reverter a internacionalizaçáo da PDVSA, mas a burocracia da companhia foi mais forte e conseguiu mantê-la. A empresa que sempre teve grande autonomia em relaçáo ao governo passou a ter um caminho institucional livre para a apertura petrolera. Esta política que liberou a entrada de capitais transnacionais nas atividades primárias, além de reduzir a soberania jurídica e impositiva, diminuiu de forma significativa os ingressos fiscais do petróleo e colocou a Venezuela em rota de colisão com os outros sócios da OPEP (BARROS, 2006). 
Durante o período de Punto Fijo vários setores se apropriam da renda petroleira; todos ganharam, embora uns tivessem ganhado mais do que outros. Foi assim até o fim da década de setenta. Com a baixa dos preços do petróleo, a renda a ser dividida caiu de maneira mais ou menos constante até o fim dos anos noventa. Alguns setores mais próximos do governo e principalmente da PDVSA, tiveram perdas menores, mas a maior parte da população perdeu muito, o que abriu espaço para surpresas eleitorais. Chávez, que era a figura pública que melhor encarnava a repulsa ao modelo estabelecido de apropriaçáo da renda, venceu as eleiçóes com uma plataforma que enfatizava aspectos "neutros" e consensuais, como o combate à corrupção. Porém em círculos menores, Chávez nunca deixou de expressar um posicionamento anti-neoliberal, a necessidade de refundar a república e uma crítica profunda à apertura petrolera.

Primeiro momento: Programa de Governo do MVR

Começaremos nossa apresentação pelo programa de governo 1999-2003, intitulado "La propuesta de Hugo Chávez para transformar Venezuela: una revolución democrática” (PMD, 1999), que é a referência mais importante da política econômica do período. Embora não seja um documento profundo ou completo ao tratar de temas econômicos, ele serviu de base para a contraposição chavista aos outros partidos e candidatos no campo econômico.

Sua vertente econômica é denominada "El proyecto de transición: cinco pólos para una nueva república" e começa com o tradicional diagnóstico do caráter mono-exportador da economia: "a dinâmica da economia venezuelana esteve decididamente vinculada ao excedente gerado por escassos produtos de exportação, havendo-se passado da mono-produção agro-exportadora a mono-produção petroexportadora"(MPD, 1999). Aspirava-se "alcançar um sistema econômico competitivo, que, apoiando-se nas vantagens comparativas e competitivas do país, gere produtos capazes de satisfazer as necessidades da população e competir com as mercadorias estrangeiras..." Ele sugere, portanto, que se promoveria a diversificação da economia como linha estratégica da política econômica. No documento se faz uma valorização do impacto da indústria petroleira na economia venezuelana e do fortalecimento da estrutura petroexportadora a partir da abertura petroleira que "é um 
capítulo contemporâneo de uma política concentradora de riquezas, concentradora de poder e concentradora de população", argumentando que a mudança desse modelo requeria uma "profunda transformação estrutural da economia venezuelana, a qual se desenvolverá no marco da V República emanada do processo constituinte". Ou seja, a solução para esse problema estrutural da economia venezuelana passava, necessariamente, por uma mudança política, na qual se redefiniria o papel do Estado como promotor do desenvolvimento, da eficiência e da igualdade.

O programa defende a idéia de que o desenho econômico da Venezuela, num passado recente, havia aprofundado uma distribuição regressiva da renda e excluído a incorporação da população à atividade produtiva. Para reverter esse comportamento era necessário "desenvolver um modelo econômico que permita a produçáo global de riqueza e justiça”. Portanto, a política macroeconômica do Plano de Governo consistiu em um conjunto de enunciados gerais sem que tivesse clara a consecuçáo de um objetivo estratégico; e a questão econômica estava longe de ser a prioridade. Este fato reforça a idéia de que o grupo político chavista se unificava principalmente pelo fato de se opor ao modelo de quarenta anos de bipartidarismo. Sabiase que queriam mudanças, provavelmente tímidas, uma mera redistribuição das benesses do petróleo que incluiria recursos para diversificação da pauta produtiva do país como forma de diminuir a dependência externa e ampliar o mercado consumidor, porém o caminho para tal finalidade só poderia ser feito com o controle por parte do governo dos recursos da companhia petroleira PDVSA, cujo comando estava descolado do executivo nacional, como veremos a seguir.

Vale também destacar que em nenhum momento o Programa de Governo sugere uma participação econômica como produtor direto. A máxima chavista propalada na campanha e reforçada no discurso de posse era: "mercado até onde for possível e Estado apenas onde for necessário”, ou seja, nenhuma ruptura com o modelo neoliberal que vigorou em praticamente todos os países da América Latina nos anos 1990. 


\section{Segundo momento: programa econômico de transição e constituição}

Chávez assume respaldado por um voto de repúdio ao período anterior, porém sem um projeto claro ou com forças políticas que sustentassem qualquer medida radical do Executivo: sequer tinha maioria no parlamento. Caso enfrentasse uma ameaça de crise econômica, poderia ser obrigado a manter a agenda dos 90 como ocorreu com Carlos Andrés Pérez e Rafael Caldera. Duas eram as condiçóes necessárias para sua manutenção e fortalecimento no poder: manter a estabilização econômica e recuperar, em alguma medida, os preços internacionais do petróleo. Sem esta combinação Chávez ficaria refém da burocracia que se apropriou do Estado durante os quarenta anos anteriores e que não teve seu poder afetado com a queda dos preços do petróleo.

O jogo combinado era um programa econômico ortodoxo de curto prazo, a rearticulação do cartel da OPEP e um plebiscito para a convocação de uma nova assembléia constituinte.

Como os programas econômicos existentes anteriormente na Venezuela, sobretudo na década de noventa, o Programa Económico de Transición 19992000 insistiu na retórica da importância de se "mudar a mão invisível do mercado com a mão visível do Estado" (GONZÁLEZ, 2001, p. 166), ou seja, reafirmar a máxima chavista do discurso de posse: "tanto mercado quanto seja possível, tanto Estado quanto seja necessário”.

Concebeu-se o Estado como protetor do interesse geral da população e, por isso, cabia a ele promover as atividades econômicas privadas e regular a intervenção dos agentes econômicos para evitar condiçôes de concorrência desleal. Além disso, cabia ao Estado estimular e favorecer a acumulação de capital físico e humano do país, não só através de políticas de estímulo ao investimento nacional e estrangeiro, mas criando as regras do jogo que garantam a segurança jurídica dos capitais que assumam o risco de incorporarse a esse esforço de transformação econômica.

O programa econômico da transição foi uma proposta para o curto prazo. Ele tinha dois propósitos bem definidos: reverter a grave situação socioeconômica existente e criar as bases para um crescimento com equilíbrio das variáveis macroeconômicas levando em conta as experiências frustradas 
recentes da Venezuela. Nas palavras do próprio plano: “enfrentar o tempo de superar o prazo peremptório, a crise econômica e social generalizada que afeta nosso país" e "planejar uma estratégia organizada para impulsionar a reativação econômica em condições de estabilidade sustentada, que supere o movimento cíclico que periodicamente destrói as conquistas em matéria de estabilização e crescimento" (MPD, 2000b).

Afirmava que o modelo de economia rentista, que havia vigorado por 40 anos na Venezuela, no qual o Estado era a correia de transmissão entre a renda petroleira e as necessidades de consumo e investimento do setor nãopetroleiro, havia se esgotado.

O programa, sustentado por Maritza Izaguirre, ministra do governo anterior e fiadora da estabilidade da política econômica pela via ortodoxa, tinha como principal objetivo abater a inflação e, talvez em um plano um pouco menor, reativar o aparato produtivo.

$\mathrm{Na}$ discussão sobre estabilização econômica, o programa de transição expressava que "as açóes específicas de estabilidade monetária, financeira e cambial têm seu pilar central em uma política fiscal constituída por reformas tributárias, ajustes de gasto, de tarifas e preços dos bens de serviço público" (MPD, 2000a).

Setorialmente, se projetou em uma política de abertura petroleira e de defesa dos preços do petróleo; na atividade agrícola se estabeleceram os chamados projetos bandeiras e, no setor industrial, o fortalecimento das pequenas e médias empresas. $\mathrm{O}$ programa assegurou também a unificação dos sistemas de financiamento e o desenvolvimento das cadeias produtivas.

Contudo, chama a atenção o fato de que nem o Programa Econômico de Governo nem o de Transição fez qualquer menção especial ao papel que deveria cumprir a agricultura no crescimento sustentado da economia; também não foram previstos planos especiais para seu financiamento. $\mathrm{O}$ programa econômico traçou três objetivos fundamentais: promover um crescimento econômico sustentado e diversificado, reduzir a inflação e aumentar o nível de empregos.

De acordo com o programa, portanto, um controle do câmbio real possibilitaria uma redução gradual da taxa de inflação dos bens tangíveis, o que, finalmente se traduziria em menores taxas de inflação na economia. 
Portanto, a diminuição da inflação se sustentaria em uma âncora cambial nominal, com a qual se ratificava a política que se adotou com a instauração do sistema de bandas cambiais em junho de 1996.

O programa de transição manteve o esquema de bandas cambiais, para o qual a política monetária deveria manter um perfil restritivo com o objetivo de evitar um eventual excesso de oferta monetária que pudesse afetar a estabilidade do tipo de câmbio e, com isso, a taxa de inflação.

A política fiscal desse período procurava uma melhora dos ingressos ordinários, principalmente os petroleiros, e uma reorientação dos gastos com o objetivo de aumentar sua produtividade mediante a redução dos organismos públicos, simplificação dos tramites e aumento do gasto de capital no orçamento.

A Política Economia da Transição reforça a idéia de que o governo Chávez, pelo menos nos dois primeiros anos de mandato, não tinha como objetivo central qualquer guinada radical no campo econômico interno. As preocupaçóes do governo pareciam ser focadas em evitar alguma crise de desconfiança interna ou externa que afetasse a economia e que inviabilizasse as mudanças institucionais que eram condição sine qua non para controlar a repartição dos recursos do petróleo, aumentar a participação de novos atores na política e enfraquecer as estruturas que sustentaram a política do país durantes o período do pacto do Punto Fijo.

A política de estabilidade foi satisfatória principalmente se analisada em conjunto com a política petroleira do período. Isso porque,

a profundidade da crise petroleira, a apatia do setor privado, a ironia e a prematura hostilidade do capital e instituições internacionais e o escasso tempo entre a eleição e a posse (fevereiro/1999) não permitiram a Chávez compor uma imediata política econômica de cunho progressista (CANO, 2002, p. 116).

Nesse tempo, o petróleo caiu ainda mais e Chávez, além do programa econômico ortodoxo, foi obrigado a aceitar um acordo com o FMI.

A despeito do discurso marcadamente "bolivariano", "integrador" e "latino-americanista", o principal objetivo da política externa de Hugo Chávez no começo de seu governo foi o de rearticular a OPEP. As primeiras 
viagens internacionais do novo presidente foram para países como Irã, Líbia e Iraque; além de dar ao mandatário um ar exótico no noticiário internacional, a empreitada converteu a Venezuela em um dos países líderes do cartel, a ponto de sediar em 2000 o segundo encontro de chefes de Estado da história da organização, em Caracas. O êxito desta política foi significativo, mesmo sem Chávez interferir na política da apertura petroleira feita pelos próprios gestores da PDVSA, a OPEP restringiu a oferta de petróleo e o preço do barril do produto que era de US\$ 9,00 no início de 1999 passou para pouco mais de US\$ $20,00^{6}$ antes dos atentados de 11 de setembro de 2001, quando o preço do petróleo disparou por motivos exógenos ao cartel.

Com o aumento do preço do petróleo, o governo tentou reativar a economia, baixando os juros e aumentando a liquidez. Com o novo aumento, recuperou-se, parcialmente a carga tributária total, porém o governo já tinha um destino para o dinheiro que diminuiu a capacidade de financiamento do governo: o FIEM $^{7}$. Isso implicou a ampliação da dívida interna do país.

Os resultados da política econômica nos anos de 1999, 2000 e 2001 foram relativamente satisfatórios. O novo governo assumiu o país em retração e o PIB teve queda acumulada de $5 \%$ em 1998/99. Nos dois anos seguintes o produto cresceu a taxas médias de $3,5 \%$ ao ano. No período foi significativo o aumento dos gastos sociais do governo, os gastos em educação passaram de 3,2\% do PIB em 1998 para 3,8\% no ano seguinte, 4,4\% em 2000 e 4,7\% em 2001. Em saúde o crescimento também foi contínuo, mas menos expressivo, passou de 1,3\% do PIB em 1998 para 1,5\% em 2001. Em infraestrutura o gasto público ficou estabilizado em $0,5 \%$ do produto. Ou seja, no geral, mesmo dentro de um plano econômico ortodoxo, o governo Hugo Chávez aumentou significativamente os gastos sociais.

\footnotetext{
${ }^{6} \mathrm{Em}$ alguma medida deve ser considerado o aumento da demanda global do produto, principalmente por parte dos EUA e da China, porém este trabalho não discutirá a questão.

${ }^{7}$ O Fondo de Estabilización Macroeconómica (FIEM) foi criado um mês antes da eleição de Chávez com o objetivo de não permitir que as flutuações dos preços do petróleo afetassem o necessário equilíbrio fiscal, cambial e monetário do país, conforme prevê o artigo primeiro da lei instituidora.
} 


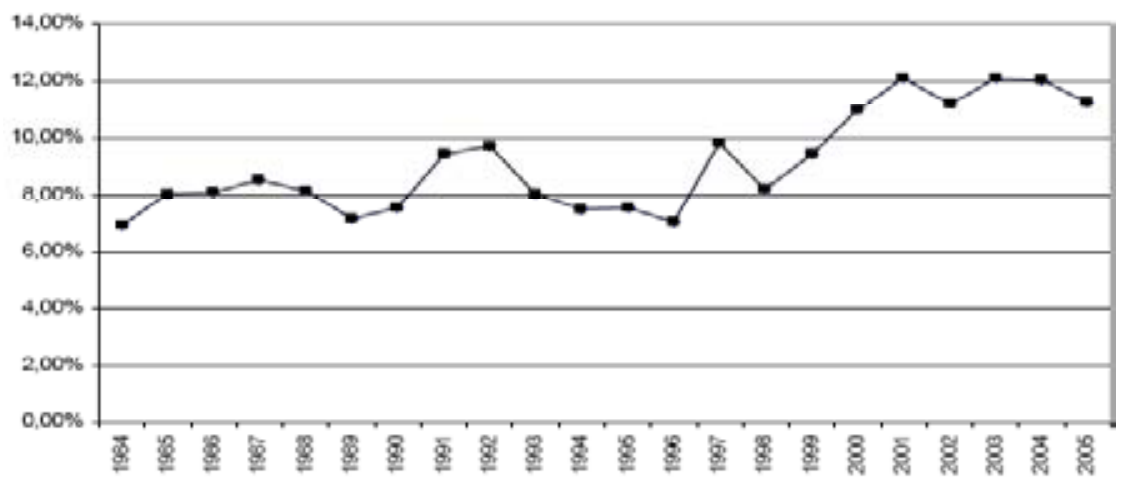

Gráfico 1 - Gastos sociais em relação ao PIB (1984 - 2005)

FONTE: Magallanes, 2006, p. 7

Os serviços da dívida pública também cresceram: 5,1\% em 1998 para $6,1 \%$ em 2001. Os índices de desemprego permaneceram estáveis, próximos a 13\%, porém a formalização cresceu de $46 \%$ em 1999 para 50\% em 2001.

O déficit público variou de forma considerável nos primeiros anos de gestão do Movimento V República. Em 1998 era de 4,1\%, passou para 2,2\% e 1,8 nos dois anos seguintes, mas voltou a crescer e foi a 4,7\% em 2001 . A contrapartida previsível foi um aumento na arrecadação. No último ano do governo anterior era de $16,4 \%$ do PIB, o menor índice da América do Sul. Com Chávez no poder passou para $16,6 \%$, ainda com o orçamento aprovado no governo anterior. Em 2000 a arrecadação foi a 19,2\% e no ano seguinte alcançou 19,8\%, o que não tirou da Venezuela o título de Estado que menos arrecada no subcontinente.

A política social apresentou como novidade o Plan Bolivar 2000. Tratouse de um esforço cívio-militar que contou com a participação de $140 \mathrm{mil}$ pessoas (sendo metade militares) para realização de reformas de infraestrutura emergenciais, utilizando mão-de-obra desempregada, e algumas políticas assistencialistas como distribuição de alimentos em áreas isoladas do país.

A manutenção da estabilidade macroeconômica, somada ao aumento nos preços internacionais do petróleo, criou um ambiente bastante favorável para as mudanças institucionais que ajudariam a consolidação do grupo chavista 
no poder. No curto prazo o MVR precisava se desvencilhar da maioria parlamentar que estava ligada aos partidos do pacto de Punto Fijo; no médio prazo precisava evitar a privatização da PDVSA e frear o processo de apertura petrolera, para abrir a possibilidade de controlar a principal riqueza do país num prazo mais longo.

Hugo Chávez havia ganhado a eleição de dezembro de 1999 com 56\% dos votos. Porém seu partido Movimento V República (MVR) não conseguiu maioria em nenhuma das duas casas legislativas. A promessa eleitoral muito pouco clara de re-fundar a república caiu como uma luva para sanar este empecilho inicial. Convocou um plebiscito sobre a necessidade de uma nova constituição em abril do ano seguinte, quatro meses depois da primeira vitória; o "sim" ganhou com mais de $80 \%$ dos votos. Na eleição para os membros da Assembléia Constituinte a vitória é ainda mais significativa: 119 dos 131 membros eleitos eram "chavistas". A nova constituição acrescentou a figura de Bolívar ao nome oficial do país, que passou a ser "República Bolivariana da Venezuela", eliminou o Senado e criou uma nova Assembléia Nacional unicameral (o que garantiria 100\% de renovação do parlamento) e estabeleceu cinco poderes constitucionais, dois a mais que a maioria dos países ocidentais; além da tríade executivo, legislativo e judiciário, foram criados os poderes eleitoral e cidadão, com o objetivo de aumentar a fiscalização e a participação direta dos cidadãos na vida política nacional e, principalmente, de destruir os alicerces do pacto de Punto Fijo, especialmente ao alterar a estrutura do poder judiciário. A Carta foi referendada por mais de $70 \%$ dos venezuelanos e se iniciou formalmente a $\mathrm{V}$ República.

A nova constituição estabeleceu, dentre outras coisas, uma nova concepção de cidadania social sob a égide da co-responsabilidade entre Estado e cidadãos. A ênfase na questão social pode ser relacionada, de acordo com Mercedes Briceño (2000, p. 15), a certas variáveis: o esgotamento dos interlocutores tradicionais, que atuaram no país desde 1960, tais como organizaçóes sindicais e partidos políticos; uma emergente sociedade civil que se sentia relegada pelos partidos; os limites do sistema representativo; e a crescente pressão das convençóes internacionais nos direitos sociais. Além disso, é nos direitos sociais que se vislumbra um possível projeto de país, onde se tornam mais agudos os dilemas da participação, da representatividade, da 
institucionalidade e, sobretudo, do sentido da democracia.

Para Aristóbulo Istúritz (2000, p. 8), as políticas sociais do período anterior à nova constituição tinham uma orientação populista e clientelista de relaçáo entre o Estado e a sociedade, na qual Estado era o grande solucionador dos problemas da população. A população por sua vez se apresentava de forma passiva, exigindo do Estado e dos Governos a resoluçáo dos seus problemas. Para o autor esse tipo de relação criou uma dependência da comunidade em relação ao Estado que era a base de uma democracia representativa tal qual se apresentava na Venezuela no período da IV República. Para a consolidação de um outro tipo de democracia, tal qual está expressa na nova Constituição, uma democracia participativa e "protagônica", a mudança dessa relação de dependência era crucial.

Dessa forma, a principal razão para a criação da nova constituição foi criar bases jurídicas para que se funde uma outra República, o que implica em reordenar o território, provocar uma mudança cultural e, ao mesmo tempo, re-legitimar as instituiçóes políticas e os poderes públicos que afetam o Estado. A nova Constituição mudou o paradigma de Estado na Venezuela, bem como criou as bases institucionais para a mudança da economia rentista para uma economia produtiva, impulsionando articulação social para que essas mudanças se concretizem.

Ícone dessas mudanças foi a alteração da definição de soberania popular. Antes concebida como:

a soberania reside no povo, que a exerce mediante sufrágio através dos órgãos do poder público; a partir de 1999 a soberania reside intransferivelmente no povo, que a exerce diretamente, pelas formas previstas na Constituição e nas leis, e de maneira indireta, através do sufrágio universal.

A nova Constituição ainda criou as bases para a retomada do controle da principal riqueza do país, o petróleo; em seu Art. $303^{8}$ estabeleceu que a PDVSA não pode ser privatizada.

\footnotetext{
${ }^{8} \mathrm{O}$ artigo 303 da Constituição Bolivariana estabeleça que "por razões de soberania econômica, política e de estratégia nacional, o Estado conservará a totalidade das ações da Petróleos de Venezuela S. A. ou do ente criado para o manejo da indústria petroleira, excetuando as das filiais, associações estratégicas, empresas e qualquer outra que se constituiu ou constitua como consequência do desenvolvimento dos negócios da Petróleos de Venezuela S. A."
} 
Portanto, este período inicial do governo Chávez foi fundamental para criar alguma coesão no grupo que chegou ao poder em 1999, garantir o corte institucional que diminuiu a margem de atuação do grupo do Punto Fijo que se apropriou do Estado por quarenta anos e criar as regras do jogo da V República.

\section{Terceiro momento: inflexão política e resposta conservadora}

A inflexão do governo Chávez começa a ser vislumbrada com o Plano de Desenvolvimento Econômico e Social da Nação 2001-2007, ganha expressão internacional com a promulgação das Leyes Habilitantes, um pacote de 49 leis que regulamentavam artigos específicos da Constituição Bolivariana de 1999, em novembro de 2001, passa por uma tentativa de golpe de Estado em abril de 2002 e termina com a mudança de controle na PDVSA, em fevereiro de 2003, após uma greve patronal-petroleira que havia começado em dezembro de 2002.

A partir do Plano da Nação 2001-07 foram traçadas as linhas mestras da política petroleira. Entre os aspectos fundamentais dessa política sobressaiu o fortalecimento da OPEP com o objetivo de assegurar o controle sobre a oferta petroleira e, consequentemente, defender os preços. "O redimencionamento dos planos e projetos da PDVSA e suas filiais, com a finalidade de adequar o montante de seus investimentos a evoluçáo do mercado energético mundial e a avaliação dos investimentos da PDVSA no exterior com o objetivo de precisar sua rentabilidade, os custos de oportunidade e segurança do mercado" era o instrumento da estratégia. Igualmente, se daria prioridade ao investimento privado nacional mediante um processo de formação de novos capitais nacionais orientados para essa atividade.

A PDVSA ainda continuava com um corpo burocrático da IV República. Embora com uma política externa muito diferenciada os gestores ainda tinham a mentalidade da "apertura petroleira" e de modo algum aceitariam perder os benefícios de grupo social mais privilegiado da Venezuela. A primeira lei chavista sobre o tema (Constituição Bolivariana de 1999) não gerou muita controvérsia, mas a Lei de Hidrocarbonetos de novembro de 2001 gerou grandes conflitos no âmbito da gerência da empresa.

Esta lei fez parte do pacote de 49 leis decretado pelo presidente Chávez 
que marcou o início da rearticulação dos setores derrotados na eleição de 1998 e na constituinte de 1999 . O pacote contou também com outras duas leis muito polêmicas: Lei de Terras e Lei de Pescas. A Lei de Hidrocarbonetos previa um aumento nos repasses, porém só para novas licenças, e uma questáo chave: a contabilidade das atividades internas e externas da companhia deveria ser feita em separado, o que explicitaria que as atividades internas geravam muitos excedentes, enquanto as externas os enormes prejuízos que garantiam a apropriação dos recursos do petróleo por uma casta da burocracia da PDVSA.

Neste momento o governo passa a ser acusado fortemente pela grande mídia, pelo sindicato patronal FEDECAMARAS e por setores conservadores de dividir o país, de atentar contra a propriedade privada e de querer implementar um regime castrista na Venezuela. O descontentamento destes setores com a política do governo culminou com o golpe de Estado de 11 de abril de 2002, que teve apoio, em maior ou menor grau, de praticamente todos os executivos da PDVSA. O golpe fracassou, mas a organização dos setores golpista fez com que em dezembro de 2002 se iniciasse uma greve patronal nacional a partir da PDVSA, que também parou quase todas as empresas transnacionais do país. O nível de produção de petróleo chegou próximo de zero e, como medida extrema para a PDVSA não suspender completamente suas atividades - o que levaria a uma grave crise de abastecimento - o governo aceitou o envio de milhares de técnicos cubanos, para trabalhar na estatal.

A partir daí somente duas opções são exeqüíveis: a renúncia do presidente ou uma reforma radical da PDVSA com a substituição de toda sua direção. A mudança não ficou restrita à direção; dos 40 mil funcionários da estatal, mais de 17 mil foram demitidos. A grande ameaça do antigo grupo gestor, de que não haveria pessoal qualificado fora da empresa para manter o alto nível de produção se mostrou improcedente com a rápida recuperação da empresa. Em pouco tempo o nível de produção já se igualava ao de 2001.

Não há como negar que a grande recuperação do preço do barril do petróleo ajudou a Venezuela e sua principal empresa a saírem da crise. Internamente, com muitas ponderaçóes, a oligarquia da PDVSA havia ajudado o governo a acelerar o passo da reforma petroleira quando se posicionou contra o país e deu legitimidade para o governo fazer o que bem entendesse com a empresa. 
Externamente, a invasão do Iraque e a questionável política do governo George Walker Bush levaram o preço do petróleo a níveis reais próximos aos da década de setenta e ampliaram de forma consistente a margem de manobra, tanto interna como externa, do governo Hugo Chávez.

O petróleo sempre foi o principal instrumento de política exterior da Venezuela, porém ele nunca foi tão usado como durante o governo Hugo Chávez. A atuação da Venezuela, sob este governo, foi muito além da rearticulação da OPEP, o país firmou acordos de cooperação energética com paises com os quais mantinha pouca relação como Argélia, Nigéria, China e Rússia; tem trocado petróleo por serviços médicos com Cuba e, cada vez mais, vendido petróleo, geralmente atrelado a outros acordos políticos, a condições muito favoráveis para diversos paises caribenhos e latino-americanos.

A reforma petroleira iniciada com a constituição e acentuada com as Leis Habilitantes de 2001 reconhecia que deveria ser restabelecido o controle do Poder Público Nacional sobre os recursos hidrocarbonetos, o direito do Estado de definir e garantir uma contribuição patrimonial pelo acesso ao recurso natural e a limitação de atividades da PDVSA a exploração, extração, transporte, refinação e distribuição de hidrocarbonetos e produtos por ela elaborados, eliminando desta forma atividades financeiras especulativas e similares. Outros passos tinham que ser dados em seguida: (1) impulsionar processos de industrializaçáo de hidrocarbonetos a fim de melhorar a composição da cesta de exportação venezuelana, (2) separar a contabilidade das atividades extrativas das atividades de transformação e comércio e (3) fortalecer a participação da Venezuela no mercado mundial de energia.

Por fim, deve-se considerar que o ingresso fiscal petroleiro é a principal fonte de recursos que dinamizam os setores não-petroleiros da economia. O controle da principal companhia do país foi fundamental para o governo Chávez realizar uma guinada na política econômica em seu governo.

O período de inflexão foi marcado por uma crise econômica com poucos precedentes fora de estado de guerra. O PIB que vinha crescendo a pouco mais de 3\% ao ano no período inicial do governo Chávez, caiu 8,8\% em 2002 e 7,7\% em 2003. O desemprego passou de 13\% da população economicamente ativa para entre $16 \%$ e $17 \%$ no período da crise de 2002 03 , sendo que ao aumento da formalização que chegara a 50\% em 2001, 
voltou ao nível de $47 \%$.

As dívidas públicas interna e externa cresceram de forma bastante considerável no período de inflexão. A dívida pública interna que era de apenas 4,3\% do PIB em 1998 já havia crescido para 8,3\% em 2000 e 11,5\% em 2001, foi para 13,7\% em 2002 e atingiu seu patamar máximo em 2003: $17,3 \%$ do PIB. A variação da dívida pública externa foi ainda mais forte; a grande queda que havia ocorrido nos primeiros anos do governo Chávez se reverteu rapidamente. No começo do governo a dívida pública externa chegava a $25,1 \%$ do PIB caiu para 18,9\% em 2001; em 2002 disparou para $29,3 \%$ do PIB e chegou a 29,6 \% em 2003. Para uma análise mais profunda do comportamento da dívida deve ser levada em conta as variaçóes negativas do produto venezuelano nos anos de 2002 e 2003. O déficit público foi mantido nos níveis de 2001 , entre $4 \%$ e $5 \%$ do PIB, porém a arrecadação cresceu de maneira constante, em 2001 correspondia a 19,8\% do PIB e em 2003 chegou a $21,1 \%$.

\section{Quarto momento: o Estado controlado e a nova política econômica}

O momento que caracterizamos como "Estados controlado" só pôde ser concretizado após o controle da produção de petróleo pelo Estado e de seus excedentes pelo governo. Logo após a greve patronal-petroleira de 2002-03 o governo Chávez lança uma nova política social, denominada missões sociais, que passam a influir na vida cotidiana de parte considerável da população venezuelana. Os recursos necessários para estas missóes não vêm dos ministérios, mas diretamente da PDVSA que a partir de maio de 2004 criou também o FONDESPA?', uma alternativa para o cumprimento dos princípios de vinculação adequada dos ingressos provenientes dos hidrocarbonetos com a economia nacional. Em julho do mesmo ano a PDVSA firmou contrato para criação de um fundo conjunto como o BANDES (Banco de Desenvolvimento Econômico e Social), que se destinava a efetuar os pagamentos necessários para execução de programas e projetos de obras, bens e serviços destinados ao desenvolvimento da infra-estrutura, atividade

\footnotetext{
${ }^{9}$ Fundo para o Desenvolvimento Econômico e Social do País, já no primeiro ano contou com mais de US\$ 2 bilhões para investimento.
} 
agrícola, saúde e educação no país. O fato das missóes não serem vinculadas diretamente a nenhum ministério, atentando contra os "bons manuais da administração pública”, é explicado pela apropriação das repartições públicas e pela resistência partidária a mudanças que os funcionários ligados a velha burocracia de Punto Fijo têm em relação ao governo Chávez. Após as lições da greve patronal-petroleira de 2002-2003, não surpreendeu o fato dos novos programas sociais serem ligados diretamente à presidência da república.

Outra mudança econômica foi o controle de capitais a partir da conturbada greve petroleira, quando a fuga de capital do país foi intensa. $\mathrm{O}$ governo limitou, de maneira bastante restritiva, as remessas para o exterior e impôs cota de importação limitada em US\$ 1000 por pessoa física, além de proibir o comércio de moeda estrangeira do país. A taxa de câmbio passou a ser fixa e corrigida anualmente. Essas medidas somadas à subida do preço do petróleo fizeram as reservas cambiais aumentarem numa velocidade jamais vista: depois de mais que dobrar, chegou a US\$ 31,05 bilhóes em 2005. Dadas estas condições muito mais favoráveis, foi possível ao governo mudar a legislação do Banco Central, o que possibilitou o uso de parte das reservas em programas sociais do poder executivo.

Um novo mecanismo, também criado em 2005, garantiu que toda a arrecadação fruto de venda de petróleo fosse distribuída da seguinte forma: até US\$ 26/barril são de posse da PDVSA que paga seus tributos, seus funcionários, reinveste, etc.; acima de US\$ 26/barril os recursos seriam destinados ao poder executivo, o qual investe em programas sociais e em novas atividades econômicas por meio do FONDEN ${ }^{10}$ e do FONDESPA.

Para Luciano Wexell Severo, economista brasileiro do Ministério de Indústria Básica e Mineração da Venezuela sete são os fatores determinantes para o crescimento econômico vigoroso a partir de 2004. São eles 1) a modificação da lei de hidrocarbonetos e aumento dos royalties cobrados das transnacionais petroleiras pelo governo; 2) adoção do "controle de câmbio"

\footnotetext{
${ }^{10}$ Os recursos do FONDEN são reservados para o financiamento de planos estratégicos de desenvolvimento em setores como: indústrias básicas, petróleo, gás, infraestrutura, transportes, habitação. Dentro destas linhas se criam empresas e se desenvolvem projetos como a nova siderúrgia venezuelana para a produção de aços especiais, uma fábrica de tubos petroleiros sem costura, três novas refinarias de petróleo, produção de madeira, as fábricas de cimento, de concentração de mineral de ferro, de laminação de alumínio, de papel e celulose, entre outros.
} 
no inicio de 2003, que aumentou em dois anos as reservas internacionais de dólares de 15 milhóes para 30 milhóes de moeda americana e possibilitou a aplicação de outras medidas; 3) nova lei do Banco Central e a criação do Fondo Nacional de Desarrollo (FONDEN), que já conta com um montante de quase US\$ 9 bilhões; 4) novo enfoque do órgão máximo de arrecadação de tributos, o SENIAT, que aumentou este ano em 60\% a arrecadação de impostos sobretudo das grandes empresas nacionais e transnacionais, historicamente morosas e evasoras; 5) ampliação do plano de investimentos públicos na plataforma de industriais básicas e conseqüente efeito multiplicador e acelerador dos investimentos privados no setor de transformador de insumos básicos em produtos de maior valor agregado; 6) aporte de US\$ 5 bilhóes em 2005 nas missóes sociais, como mecanismos de emergência para pagar a imensa dívida social acumulada, diminuir o desemprego e combater a inflação; e 7) o trabalho do Ministério da Agricultura e Terras (MAT) para resgatar e ativar produtivamente um milhão e meio de hectares de latifúndios improdutivos, fortalecendo o Plan Siembra 2006 e incorporando milhares de camponeses e trabalhadores ao processo produtivo.

A importância da análise destes sete pontos é que a maioria deles não constavam no programa de governo do MVR e alguns deles não faziam parte do Plano da Nação 2001-07, embora todos estejam hoje incluídos entre as principais políticas públicas do governo Hugo Chávez. A modificação da lei de hidrocarbonetos já era apresentada desde a campanha eleitoral de 1998 como um dos pontos cruciais para uma política consistente de desenvolvimento nacional, porém a proposta estava muito longe da magnitude que a reforma do setor chegou após a greve patronal-petroleira de 2002-03. A adoção do controle de câmbio não estava prevista em nenhum dos documentos chavistas; pelo contrário a constituição de 1999 previa a independência do Banco Central ${ }^{11}$ como planejador e executor de política monetária e cambial, alem da coordenação macroeconômica; o próprio BCV reconhece que o controle de câmbio só foi colocado em prática devido a enorme fuga de capitais que ocorreu durante a greve patronal-petroleira de 2002-03 que ameaçou gravemente as reservas do banco, em janeiro de 2003 as reservas

\footnotetext{
${ }^{11} \mathrm{O}$ artigo 320 da Constituição Bolivariana estabelece que "no exercício de suas funções o Banco Central da Venezuela não estará subordinado a diretivas do Poder Executivo e não poderá convalidar ou financiar políticas fiscais deficitárias".
} 
caíram para apenas US\$ 14 bilhóes, trinta meses depois já superavam os US\$ 30 bilhóes. O mesmo pode-se afirmar sobre o FONDEN, as missóes (BARROS, 2006) e as indústrias básicas. Apenas a reforma da Seniat ${ }^{12}$ pode ser apontada como prevista desde que Chávez chegou ao poder, a forma e o foco da tributação foram muito próximos ao que estava exposto no Programa de Governo.

Os resultados do setor petroleiro também foram bastante modificados no período. Os royalties ${ }^{13}$ que ficavam próximos a $4 \%$ do PIB nos primeiros anos do governo, chegaram a 8,7\% do produto venezuelano no ano de 2005 . Os dividendos do setor petroleiro que atingiram 4\% do PIB em 2001, não passaram de $1 \%$ em 2005.

A despeito do crescimento dos preços internacionais do petróleo a participação do setor petroleiro na economia perdeu importância. O crescimento econômico do período foi surpreendente. O PIB venezuelano cresceu 17,8\% em 2004, 9,3\% em 2005, o primeiro trimestre de 2006 confirmou os anualizados $9,3 \%$ do ano anterior. O surpreendente é o fato de que o crescimento do PIB-não petroleiro é muito mais significativo que o do PIB-petroleiro. A economia não-petroleira representava $70,5 \%$ do produto no primeiro ano do governo Chávez, no ano de 2005 superou a barreira dos $76 \%$. O PIB-petroleiro representava $20,1 \%$ e passou para $14,9 \%$ no mesmo período. A diferença fica por conta dos "impostos líquidos sobre o produto". A inflação anualizada que beirou os 30\% em janeiro de 2003 caiu para $14,4 \%$ em dezembro de 2005 . Tanto a taxa de inflação como a taxa de crescimento do ano de 2005 foram melhores que as previsóes do Banco Central da Venezuela feitas um anos antes (BCV, 2006).

A análise mais detalhada das variaçóes recentes do PIB venezuelano fortalece a idéia de sustentabilidade do crescimento após 2004. O PIB do setor manufatureiro foi o que teve maior crescimento, o setor que correspondia a 14,7\% do produto em 2003 passou a representar 16,7\% dois anos depois. Medidas governamentais como o "Acordo Macro para a Reativação Industrial e a Transformação do Modelo Produtivo" e do "Decreto para a Criação do

\footnotetext{
${ }^{12}$ Órgão federal responsável pela tributação. No governo Chávez a arrecadação subiu de forma bastante expressiva. Em 1999 correspondia a 21\% do PIB, em 2005 passou a corresponder a 35\% do produto venezuelano.

${ }^{13}$ Participação na receita ou quantidade fixa que se paga ao Estado devido à exploração de petróleo, seja pela PDVSA ou por qualquer outra empresa do setor.
} 
Subministério de Matérias Primas ao Setor Transformador Nacional” que visam reduzir as exportaçóes primárias e garantir insumos básicos à industria nacional reduziram significativamente as importaçóes de bens para consumo final de 37,6\% do total de importaçóes em 2003 para 24,2\% dois anos depois. A contrapartida foi um aumento nas aquisiçóes de bens para a Formação Bruta de Capital Fixo de 12,3\% para 25,7\% no mesmo período. Para SEVERO (2006) estes fatores demonstram o esforço e o resultado do "processo de industrialização soberana em marcha", de modo que podemos verificar numericamente as mudanças de uma economia rentista para uma economia mais produtiva, com a maior diversidade de produtos desde o período da descoberta do petróleo no país.

\section{Considerações finais}

A chegada de Hugo Chávez ao poder não vislumbrava, pelas forças que o apoiavam, por seu discurso e pelo programa de governo, mudanças tão significativas quando as que se apresentaram a partir de 2003. Seu objetivo inicial foi manter a economia estável, dentro das diretrizes macroeconômicas consolidadas nos anos noventa, para realizar algumas mudanças institucionais significativas, notadamente a rearticulação do cartel da OPEP, no plano externo e, no plano interno, a nova Constituição de 1999. Esta Carta permitiu diminuir os poderes dos partidos políticos tradicionais e do judiciário constituído no período histórico anterior e, ao mesmo tempo, aumentou a participação política direta e personificou na figura do presidente as mudanças, e as perspectivas de mudanças, do país.

Entretanto, a inflexão da política econômica venezuelana só ocorreu após a tentativa de golpe de Estado e a greve patronal-petroleira de 2002-2003 e a conseqüente mudança na relação entre Estado e PDVSA. O estopim desses fatos pode ser entendido como uma reação desproporcional da oposição às mudanças realizadas pelo governo com ampla participação popular e dentro dos marcos da legalidade. O país, o governo e a oposição saíram debilitados desse processo.

Os problemas econômicos provocados por três meses de quase ausência de atividades industriais foram muito amenizados pela forte alta nos preços internacionais do petróleo. O controle da PDVSA fez com que o executivo pudesse ampliar sua atuaçáo por meio de programas sociais realizados à 
margem das estruturas tradicionais do Estado (parlamento, ministérios) e aumentar a relação direta entre o mandatário maior e a população, especialmente dos setores mais carentes. O papel protagonizado pela oposição a levou a uma crise de identidade: reivindicavam a legalidade, mas tinham acabado de tentar um golpe de Estado; reivindicavam a democracia, mas o país jamais tivera visto tanta participação popular na política.

O executivo foi obrigado, pelas circunstâncias da crise de 2003, a aplicar algumas medidas que não estavam presentes no programa de governo ou no Plano de Desenvolvimento da Nação, como o controle da saída de capitais, que somadas a criação de novas instituições, como os ministérios de economia popular e de indústria básica, algumas mudanças na legislação, como a nova lei do Banco Central, e o aumento considerável da carga tributária ${ }^{14}$ permitiram ampliar fortemente a margem de ação do Estado.

Dessa forma, a experiência bolivariana na Venezuela, após oito anos no governo, pode ser considerada a primeira ruptura de um governo sulamericano com as diretrizes do Consenso de Washington. Quando chegou à presidência em 1998, nenhum outro presidente do subcontinente apresentava simpatia pelas políticas que Chávez protagonizaria no período posterior, porém em 2006 esse quadro mudou consideravelmente, não pelo sucesso do governo Hugo Chávez, mas pelo fracasso da aplicação da agenda neoliberal na região. As eleiçôes de Néstor Kirchner (Argentina), Lula da Silva (Brasil), Tabaré Vásquez (Uruguai), Evo Morales (Bolívia), Michele Bachelet (Chile) e Rafael Correa (Equador) refletem, em maior ou menor medida, essa situação.

O quadro político atual da América do Sul expressa a tentativa de reconstruir (ou construir) Estados que foram comprometidos nos anos noventa. As diferenças desses processos de país para país decorre muito menos da formulação teórica dos grupos que chegam ao poder e muito mais das condiçóes e complexidades sociais, institucionais e econômicas de cada lugar. Assim, a aparente maior radicalidade dos governos Rafael Correa e Evo Morales é conseqüência da situação mais trágica das instituiçóes e da economia desses países e não da pretensa vocação autoritária desses governos,

\footnotetext{
${ }^{14}$ A relação entre impostos totais e PIB (carga tributária) passou em de 19,00\% em 1998 para 25, 54\% em 2001, 27,95\%
} em 2003 até chegar a 35,06\% em 2005. 
como expressa a concepção da maior parte dos analistas. Se Hugo Chávez é ou não paradigmático para esses governos só os próximos anos dirão 


\section{Referências Bibliográficas}

BANCO CENTRAL DE VENEZUELA. Informe a la Asamblea Nacional sobre los resultados económicos del año 2005. Caracas: BCV, 2006.

BAPTISTA, Adrubal. Bases cuantitativas de la economia venezolana, 18301989. Caracas: Comunicaciones Corporativas D., C.A., 1991.

BARROS, Pedro Silva. Constituição, petróleo e políticas sociais na Venezuela Bolivariana (1999-2005). In: ENCONTRO NACIONAL DE ECONOMIA POLÍTICA, 11., 2006, Vitória. Anais... Vitória: Sociedade Brasileira de Economia Política (SEP), 2006.

BATISTA, Paulo Nogueira. O Consenso de Washington, a visão neoliberal dos problemas latino-americanos. São Paulo: Pedex (Programa da Dívida Externa), Caderno 6, 1994.

BOUÉ, Juan Carlos. El programa de internacionalización en PDVSA: ¿Triunfo estratégico o desastre fiscal? Revista Venezolana de Economía e y Ciencias Sociales, Caracas, Facultad de Ciencias Económicas y Sociales, Universidad Central de Venezuela v. 8, n. 2, mayo-agosto. 2002.

BRICEÑO, Mercedes P. La Constitución de 1999 y los derechos sociales. In: MAINGON, Thais (Org.). La cuestión social en la Constitución Bolivariana de Venezuela. Caracas: CENDES, 2000.

BUENAÑO, Gilberto. Entrevista concedida ao autor. Caracas, 2005.

CANO, Wilson. Venezuela: limites para uma nova política econômica. Economia e Sociedade, Campinas, Instituto de Economia da Unicamp, v. 11, 2002.

GIORDANI, Jorge. Proyectos estratégicos para una nueva etapa. Revista Cuestión, Caracas, dic. 2005.

GONZÁLEZ, Franklin. El Pacto de Punto Fijo, la Agenda Venezolana y el Programa Económico de Transición 1999-2000. Desarrollo y sus problemas. Caracas: Universidad Central de Venezuela, 2001.

GOTT, Richard. À sombra do libertador: Hugo Chávez Frías e a transformação da Venezuela. São Paulo: Editora Expressão Popular, 2004. 
ISTÚRITZ, Aristóbulo. Lo social en la nueva Constitución Bolivariana. In: MAINGON, Thais (Org.). La cuestión social en la Constitución Bolivariana de Venezuela. Caracas: CENDES, 2000

LANDER, Luis E. La reforma petrolera del gobierno Chávez. Revista Venezolana de Economía e y Ciencias Sociales, Caracas, Facultad de Ciencias Económicas y Sociales, Universidad Central de Venezuela, v. 8, n 2, p. 185- 188, mayoagosto. 2002.

MAGALLANES, Rodolfo. La igualdad en la República Bolivariana de Venezuela (1999-2005). In CONGRESSO LATINO-AMERICANO DE CIÊNCIA POLÍTICA, 3., 2006, Campinas. Anais... Campinas: ALACIP, 2006.

MALAVÉ MATA, Hector. Los extravíos del poder: euforia y crisis del populismo en Venezuela. Caracas: Ediciones de la Biblioteca Universidad Central de Venezuela, 1987.

MINISTERIO DE PLANIFICACIÓN Y DESARROLLO - MPD. 20002003: 3 años de la V República - Venezuela construye su camino. Caracas, 2004. Disponible en: http://www.mpd.gov.ve.

. Programa de gobierno la propuesta de Hugo Chávez para continuar la revolución. Caracas, 2000a. Disponible en: http://www.mpd.gov.ve.

. Programa Económico de Transición 1999-2000. Caracas, 2000b. Disponible en: http://www.mpd.gov.ve.

. Hacia una Venezuela productiva. Caracas, 2004. Disponible en: http://www.mpd.gov.ve.

MOMMER, Bernard. Venezuela: un nuevo marco legal e institucional petrolero. Revista Venezolana de Economía e y Ciencias Sociales, Caracas, Facultad de Ciencias Económicas y Sociales, Universidad Central de Venezuela, v. 8, n. 2, p. 201-208, mayo-agosto 2002.

. Petróleo global y Estado Nacional. Caracas: Comala.com, 2003.

MOVIMIENTO V REPÚBLICA. Una revolución democrática: la propuesta de Hugo Chávez para transformar la Venezuela. Caracas: Programa Eleitoral, 1998. 
SEVERO, Luciano Wexell. Venezuela: petróleo semeando emancipação e crescimento econômico. Caracas, 2006. Disponible en: http://www. voltairenet.org/article141468.

SOSA PIETRI, Andrés. Vinculaciones internacionales de la industria petrolera venezolana: OPEP, AIE, OLADE, ARPEL y Bloques Economómicos Regionales en América. In: CONGRESO VENEZOLANO DE PETRÓlEO, 5., 1994, Caracas. 